\title{
Federal Tax Competition - How Does the Institutional Structure of a Country Change Tax Outcomes?
}

\author{
Lisa Tillmann and Berthold U. Wigger \\ Karlsruhe Institute of Technology \\ Chair of Public Finance and Public Management \\ Kaiserstr. 12 \\ 76131 Karlsruhe \\ Germany
}

lisa.tillmann@kit.edu_berthold.wigger@kit.edu

September 21, 2010

\begin{abstract}
The interrelations of taxation and federal structure have been extensively analysed from various perspectives. The present paper looks at a very basic model of two competing countries of different institutional structures. It systematically examines how the tax rates set at each level of both countries vary in a given setting, where either two unitary countries compete for mobile tax base, a federal and a unitary country, or both countries are organised as federations. The paper discusses whether or not tax rates set in every jurisdiction will be too high or too low in equilibrium. The externalities triggered by a tax regime change are analysed and the respective impact on revenues is considered. The results essentially hinge on the relative strategic interaction of tax rates, as well as the elasticity of the tax base for a given tax hike.
\end{abstract}

JEL classification: $\mathrm{H} 25, \mathrm{H} 77$

Key words: Federalism, Capital taxation, Tax externalities 


\section{Introduction}

The literature on tax competition has, over the past years, developed quite extensively. Numerous papers have considered the role of horizontal tax competition in various settings. ${ }^{1}$ The central result ${ }^{2}$ is that tax rates will be set inefficiently low in equilibrium as a consequence of horizontal externalities triggered by each government neglecting the effect its own choice of tax rates has on revenues of the competing jurisdictions. Early models, such as Tiebout (1956) or Brennan and Buchanan (1977, 1980) had focused on revenue-maximising Leviathan governments, where inefficiently low taxation from the perspective of the government was welfare-increasing by curbing the Leviathan's self-serving ambitions. In contrast, in their seminal papers, Wilson (1986) as well as Zodrow and Mieszkowski (1986) considered models of welfare-maximising governments and established the view of welfaredecreasing effects of tax competition, in which inefficiently low tax rates led to inefficiently low levels of public good provision. Tax base overlap between different levels of government as a possible source of inefficiencies was first characterised by Cassing and Hillmann (1982), Flowers (1988) or Johnson (1988). The resulting vertical tax externalities that could lead to inefficiently high tax rates reached the focus of attention only by the late 1990s, when Dahlby (1996) considered tax base overlap for welfare-maximising governments and Keen (1998) examined vertical externalities in a federation of Leviathans.

Over the last decade, a strand of literature has then focused on the implications of federal structure, that is, multileveled taxation of identical or overlapping tax bases within a country. With the identified effects pointing in different directions ${ }^{3}$, which of these two dominates in a given setting, was then the central question focused on. ${ }^{4}$ These models typically examine federations in a more or less closed-economy setting, where only a single country is

\footnotetext{
${ }^{1}$ For an overview of the literature on international tax competition see Wilson (1999) or Wildasin and Wilson (2004).

${ }^{2}$ See, for example, Mintz and Tulkens (1986).

${ }^{3}$ That is, horizontal tax competition leading to inefficiently low taxation (as in Wildasin (1989) or Karkalakos and Makris (2008)) and vertical tax externalities pointing towards inefficiently high taxation (see, for example, Wigger and Wartha (2004)).

${ }^{4}$ See, for example, Keen and Kotsogiannis (2002, 2003), Fenge and Wrede (2007), or Tillmann and Wigger (2010).
} 
considered. What has, however, seen little attention, is the question in which way the institutional structure influences the outcome when a federation is modelled in a two-country setting. ${ }^{5}$

With a multitude of papers assessing the effects of horizontal competition in terms of several unitary states engaging in competition with each other, and few approaches assessing the interaction of two federal states or a federal and a unitary state, what we have found to be missing was an integrated approach that systematically compares within one distinct setting, how a change in the institutional design of two countries competing for mobile tax base influences tax rate choices. We thereby hope to give a systematic overview of the occuring changes, that are not affected by differences in the model specifications.

The relevance of this excercise becomes apparent if the enlargement of the European Union is borne in mind. It currently consists of 27 member states, each of which have their own historically grown institutional structure. EU membership grants the full liberalisation of capital flows between countries. Hence, every member state will be subject to intensive competition for capital tax base, ${ }^{6}$ such that it is a relevant question whether it will make a difference for a country such as Germany to be competing in tax rates with another federal country or a unitary country such as France. From a different perspective, with respect to a possible further enlargement, it might be a different thing for Germany or France when new member states join the European Union with an institutional structure that is unitary or federal. What is more, the political reality sees member states acting as independent entities aiming to maximise their own revenue, while neglecting to a large degree the effect their own choices have on other member states. That is, an-

\footnotetext{
${ }^{5}$ Wilson and Janeba (2005) consider two federal countries competing for capital in a model in which the degree of decentralisation serves as a strategic tool of tax competition, yet their analysis does not explicitly recognise the distinct effect of each federal level on the efficiency of tax rates chosen. Wrede (1996) examines the changes that occur when a federal and a unitary state interact in a simultaneous-move game. For the interaction of several federations, Wrede (2002) develops a general model of simultaneously moving Leviathan governments. Along the same lines, Grazzini and Petretto (2007) examine whether a welfare-maximising federal and a unitary country engaging in Stackelberg tax competition will over- or undertax in their respective jurisdictions.

${ }^{6}$ There have been various contributions examining the effect of increased capital tax competition on EU tax rates, with recent examples including Karkalakos and Makris (2008) or Davies and Voget (2009).
} 
other relevant question to ask with respect to the European Union is whether EU-wide budgets would profit from further integration and coordination between member states, and what role intensified capital tax competition plays in that context.

Hence, the approach of the paper is the following: Instead of adding another layer to the existing models of federal taxation, it gives an overview of how tax rates set by two countries competing for mobile capital will change with different organisational structures of the states. The aim is to strip the applied model of all unnecessary complexity, in order to keep it as simple as possible and to add clarity to the results. A sequential-move game with revenue-maximising Leviathan governments ${ }^{7}$ is examined, which, to our knowledge, has not been treated in the existing literature. We first consider a baseline scenario of two unitary states competing over mobile capital, where, obviously, only horizontal effects occur. The model is then extended to a second scenario in which one country is unitary and another is a federation. In a third step, the analysis is carried out for the case of two federations interacting in the very same setting as before. The aim is to verify the classic result of Leviathan governments being restrained by tax competition with other countries and to describe the respective externalities at work in each setting and the efficiency of chosen tax rates. ${ }^{8}$ The impact of a tax hike in one jurisdiction on revenues in other jurisdictions is taken into consideration, as well as that of coordinated tax hikes on individual and consolidated revenues.

The paper is setup as follows: Section 2 gives a general overview of the model, while sections 3,4 , and 5 deal with the analysis of the three cases

\footnotetext{
${ }^{7}$ The consideration of a Leviathan-government as opposed to a welfare-maximising decision-maker is, of course, subject to discussion. There have been numerous attempts to verify the existence of a Leviathan government following the well-known hypothesis by Oates $(1972,1985)$. Work on that matter continues, with findings in favour (as, for example, Bruelhart and Jametti (2007)), against (Berberich and Metzler (2005)) or reaching no definite conclusion (see, for example, Baskaran (2010)). A recent survey on empirical studies is given by Yeung (2009). From a theoretical point of view, the Leviathan approach yields a relatively easy to handle model with fairly clear-cut results, which makes it quite attractive.

${ }^{8}$ The efficiency of tax rates, that is, in such that from the perspective of a Leviathan government, a tax will be optimal if it maximises revenues. Obviously, it will be inefficiently high, if revenues rise by a drop in the respective tax rate, or too low in the reverse case.
} 
outlined above, that is, two unitary countries (3), a unitary and a federal country (4) and two federal countries (5) competing over capital tax base. Section 6 concludes by summarising and discussing the results and possible policy implications.

\section{The Model}

We now give a very brief overview of the basic model applied, which will be further specified in each of the following sections. The analytical framework is set up by two countries $A$ and $B$ competing for mobile capital with each other. Country A (B) is inhabited by $n(m)$ individuals, who are immobile and each endowed with one unit of perfectly mobile capital. ${ }^{9}$ Individuals choose to invest either in country $A$ or country $B$, while no cost is faced for international investment.

The capital available in each jurisdiction is used for production, where we consider a constant returns to scale production function, which is identical in all jurisdictions and at least twice continuously differentiable. It displays diminishing returns to scale in its mobile input factor, capital. Per-capitaproduction in country $C=A, B$, denoted as $y_{i C}$, is then determined by

$$
y_{i C}=f\left(k_{i C}\right)=f^{\prime}\left(k_{i C}\right) k_{i C}+\pi_{i C}
$$

where $k_{i C}$ is the per-capita amount of capital employed in country $C$. Assuming that firms are profit maximisers, $f^{\prime}\left(k_{i C}\right) k_{i C}$ is then the income of per-capita-capital employed in country $C . \pi_{i C}$ denotes the rental income accruing to each consumer living in country $C$ from an immobile factor. Hence, in country $C$

$$
\pi_{i C}=f\left(k_{i C}\right)-f^{\prime}\left(k_{i C}\right) k_{i C},
$$

from which follows that

\footnotetext{
${ }^{9}$ These two assumptions apply to the case of the European Union, where capital moves freely between member states. The mobility of citizens is - by law - also granted (except for the 'new' member states, where labour market protectionism led to the mobility of the labour force being somewhat limited, at least until 2014 (European Union (2009)), yet given language and (to some extent) cultural barriers, labour mobility is significantly less pronounced, which corresponds with the assumptions of the model.
} 


$$
\pi_{i C}^{\prime}=-k_{i C}
$$

Each individual derives utility from consumption financed by individual rental income $\pi_{i}$ taxed at the exogenous rate $\theta^{10}$, and the return on capital investments, which is taxed at a specific rate by each jurisdiction. Hence, they aim to maximise the net return on capital investments $\rho=f^{\prime}\left(k_{i C}\right)-$ $\tau_{i C}$, where $f^{\prime}\left(k_{i C}\right)$ is the marginal product of per-capita capital invested in each country $C$ and $\tau_{i C}$ is the total tax burden imposed on capital in each jurisdiction, which will all be further specified in the proceeding sections. It follows that the amount of capital invested in each country is a function of the net return to capital and the capital tax rate each jurisdiction chooses. That is, $k_{i C}=k_{i C}\left(\rho+\tau_{i C}\right)$, such that, applying the implicit function theorem,

$$
k_{i C}^{\prime}=\frac{1}{f^{\prime \prime}\left(k_{i C}\right)}<0 .
$$

The total amount of capital available within the two countries is given by

$$
n+m=K_{A}\left(\rho+\tau_{A}\right)+K_{B}\left(\rho+\tau_{B}\right),
$$

where $K_{C}=\sum_{i} k_{i C}$ denotes the total amount of capital invested in each country $C=A, B ; \rho$ is the net return on capital (which will be further specified and seen to be equal across jurisdictions in the proceeding sections) and $\tau_{C}$ is the total tax burden on capital invested in the respective country. The governments are assumed to act as Leviathans, hence they aim to maximise their income from taxation of capital and rents in a non-cooperative oneshot Nash game, while being constrained as a consequence of the mobility of capital tax base.

\section{Two Unitary Countries}

We will first consider the case of two unitary countries $A$ and $B^{11}$ competing for capital. The setup is solved by backward induction as a two-stage game

\footnotetext{
${ }^{10} \theta$ may be divided into a regional $(\delta)$ and a federal $(\Delta)$ share, such that $\theta=\delta+\Delta$ in a federation.

${ }^{11}$ Here, obviously, $n=0$.
} 
in which both governments act as Nash players simultaneously choosing their tax rate taking that of the other jurisdiction as given, while the individuals subsequently make their investment decisions. Each of the following subsections characterises one particular stage of the game. Production is defined as in section 2 .

\subsection{Capital Investment}

Each individual has the option of investing capital at home or abroad, facing a net return given by

$$
\rho=f^{\prime}\left(K_{C}\right)-T_{C}
$$

in which $f^{\prime}\left(K_{C}\right)$ denotes the marginal product of the capital invested and $T_{C}$ is the corresponding tax rate levied within the jurisdiction of country $A$ or $B$ respectively. Given perfect capital mobility, non-arbitrage will lead to the net return on investment being equal across both countries, such that $\rho=f^{\prime}\left(K_{A}\right)-T_{A}=f^{\prime}\left(K_{B}\right)-T_{B}$ implying that $\rho=\rho\left(T_{A} ; T_{B}\right)$. Total capital supply is given by

$$
n+m=K_{A}\left(\rho+T_{A}\right)+K_{B}\left(\rho+T_{B}\right)
$$

with $\rho=\rho\left(T_{A} ; T_{B}\right)$, from which follows that:

$$
\begin{array}{cc}
\frac{\partial \rho}{\partial T_{A}}=-\frac{\frac{\partial K_{A}}{\partial T_{A}}}{\frac{\partial K_{A}}{\partial \rho}+\frac{\partial K_{B}}{\partial \rho}}<0 & \in[-1 ; 0), \\
\frac{\partial \rho}{\partial T_{B}}=-\frac{\frac{\partial K_{B}}{\partial T_{B}}}{\frac{\partial K_{A}}{\partial \rho}+\frac{\partial K_{B}}{\partial \rho}}<0 & \in[-1 ; 0) .
\end{array}
$$

\subsection{Government Objectives}

For country $A$, the objective can be described the following way: 


$$
\max _{T_{A}} R_{A}=T_{A} K_{A}\left(\rho+T_{A}\right)+\theta \pi_{A}\left(\rho+T_{A}\right),
$$

that is, it aims to maximise revenues $R_{A}$ generated from the taxation of capital and rental income by choice of the tax levied on capital within its jurisdiction. Each government plays Nash, that is, upon choosing its tax rate, it takes the other country's tax as given. Bearing in mind that $\rho=\rho\left(T_{A} ; T_{B}\right)$ we can describe the first-order condition of country $A$ 's government by

$$
\frac{\partial R_{A}}{\partial T_{A}}=K_{A}\left(\rho+T_{A}\right)+T_{A} K_{A}^{\prime}\left(\frac{\partial \rho}{\partial T_{A}}+1\right)+\theta \Pi_{A}^{\prime}\left(\frac{\partial \rho}{\partial T_{A}}+1\right)=0 .
$$

That is, $A$ will take into account that its tax rate choice will have a direct tax income effect, as depicted by the first term on the right hand side of (2). The second and the third term imply that the government will also incur a change in tax base. For one, capital tax base will be reduced by investors withdrawing capital and investing elsewhere instead as a consequence of the higher tax burden. On the other hand, the resulting shift in overall net return on capital (due to higher tax rates and the resulting reduction in capital productivity in the other region triggered by the relocation of investment) will again attenuate the capital tax base effect. The same applies to the reduction in rental income. Yet, each government accounts for these effects only insofar as its own tax base is concerned, while not taking into account that it triggers a positive horizontal externality affecting the tax base by the neighbouring country. For simplicity, using (1), equation (2) can be rewritten as

$$
\left.\frac{\partial R_{A}}{\partial T_{A}}=K_{A}\left(\rho+T_{A}\right)+\left(T_{A} K_{A}^{\prime}-\theta K_{A}\right)\left(\frac{\partial \rho}{\partial T_{A}}+1\right)\right]=0,
$$

where the first term on the right hand side is the tax revenue effect and the second term is the tax base effect. Given that country A's optimal choice of tax rates depends on the tax rate chosen by the other country's government (and the same reasoning holds for the government in country $B$ ), equilibrium is characterised by $T_{A}=T_{A}\left(T_{B}\right)$ and $T_{B}=T_{B}\left(T_{A}\right)$, such that $\rho=\rho\left(T_{A}\left(T_{B}\right) ; T_{B}\left(T_{A}\right)\right)$. In order to determine whether from the perspective of the Leviathan government tax rates thus chosen will be too high or too low 
in equilibrium, we consider a coordinated tax hike of both countries, whose effect on $A$ 's revenues is given by

$$
\left.\frac{\partial R_{A}}{\partial\left(T_{A}+T_{B}\right)}=K_{A}\left(\rho+T_{A}\right)+\left(T_{A} K_{A}^{\prime}-\theta K_{A}\right)\left(\frac{\partial \rho}{\partial T_{A}}+\frac{\partial \rho}{\partial T_{B}}+1\right)\right] .
$$

To gain insight on the sign of (4), we substract (3), which is zero, from (4) to have

$$
\frac{\partial R_{A}}{\partial\left(T_{A}+T_{B}\right)}-\frac{\partial R_{A}}{\partial T_{A}}=\left(T_{A} K_{A}^{\prime}-\theta K_{A}\right)\left(\frac{\partial \rho}{\partial T_{B}}\right)>0
$$

The analogous expression holds for country $B$. That is, revenues could be increased by a coordinated tax hike in both countries, given that governments do not take into account the horizontal effects triggered by their choice of tax rates. That corresponds with the classic result that horizontal competition restrains Leviathan governments in their revenue-maximising intentions.

\section{Unitary and Federal Country}

With the interaction of a unitary and a federal country the situation becomes slightly more complex. Country $A$ is divided into $n$ regions each inhabited by a single consumer endowed with one unit of capital. Country $B$ is unitary and inhabited by $m$ individuals possessing one unit of capital each. ${ }^{12}$ Inhabitants are assumed to be evenly distributed across their home jurisdiction. The situation is analysed by backward induction in a three-stage game. First, the governments at the federal level set their tax rates. They act as a Stackelberg leader towards the regional governments while engaging in Nash competition with each other. Subsequently, the regional governments in country $A$ choose their tax rates as Nash players, bearing in mind the tax rates set by the federal governments. Finally, the individuals decide where to invest the capital available to them.

\footnotetext{
${ }^{12}$ To be precise: For symmetry reasons, $B$ is assumed to be divided into $m$ regions each inhabited by one individual, yet the taxation of capital is centralised, such that one uniform national tax rate is levied.
} 


\subsection{Capital Investment}

Individuals derive utility from consumption, which is financed by the net return on investment plus the after-tax rental income. The utility maximising individual living in country $A$ then has the choice of investing his capital at home, in any other region of the federation or abroad (in country $B$, that is). Likewise, each inhabitant of country $B$ chooses to invest inside his home country or abroad, in any of the regions of country $A$. Hence, total capital supply in one region of country $A$ is given by

$$
k_{A i}=k_{A i N A T}+k_{i B}^{*}
$$

where $i=1, \ldots, n$ stands for each region in country $A, k_{A i N A T}$ denotes the amount of capital available in one region of country $A$ that is actually invested in country $A, k_{i B}^{*}$ depicts the amount of capital available in country $B$ that is invested in region $i$ of country $A$.

Total capital supply in any of country $B$ 's regions is given by

$$
k_{B}=k_{B N A T}+k_{A}^{*},
$$

where $k_{B N A T}$ denotes the amount of capital available in country $B$ that is actually invested in country $B, k_{A}^{*}$ depicts the amount of capital available in country $A$ that is invested in country $B$.

All capital invested inside region $i$ of country $A$ will be subject to the consolidated tax rate $\tau_{A i}=t_{A i}+T_{A}$, where the former denotes the tax levied by region $i$ and the latter denotes the tax levied by the federal government in country $A{ }^{13}$ All capital invested inside country $B$ will be taxed at rate $T_{B}$. Hence, the investment decisions for one individual living in $A$ or $B$ respectively can be described the following way:

\footnotetext{
${ }^{13}$ We assume that the federal government will set one uniform tax across its jurisdiction (which does not have to be the case, as Wrede (2002) points out).
} 


$$
\begin{aligned}
& \rho_{A N A T}=f^{\prime}\left(k_{A i}\right)-\tau_{A i}, \\
& \rho_{A I N T}=f^{\prime}\left(k_{B}\right)-T_{B}, \\
& \rho_{B N A T}=f^{\prime}\left(k_{B}\right)-T_{B}, \\
& \rho_{B I N T}=f^{\prime}\left(k_{A i}\right)-\tau_{A i},
\end{aligned}
$$

in which $\rho_{A N A T}$ denotes the net return to capital an individual living in country $A$ generates by investing in $A, \rho_{A I N T}$ is the net return an individual living in $A$ generates from investing abroad, that is, in country $B$. Analogously, $\rho_{B N A T}$ is the net return to an individual living in $B$ from investing inside his home country and $\rho_{B I N T}$ is the net return for an individual from $B$ investing abroad. Capital invested in a region of $A$ will then earn its marginal product, which depends on the total amount of capital supplied in that region, that is, $f^{\prime}\left(k_{A i}\right)$, net the tax burden applicable, that is, $\tau_{A i}$. Capital invested in $B$ will earn its marginal product depending on the total amount invested in $B$ net the respective tax, which is $T_{B}$. Given decreasing returns to scale, nonarbitrage must lead to the net return on capital to be equal across regions ${ }^{14}$ and countries, such that $\rho=f^{\prime}\left(k_{A i}\right)-\tau_{A i}=f^{\prime}\left(k_{B}\right)-T_{B}$, which implies that $\rho=\rho\left(t_{i=1, \ldots, n} ; T_{A} ; T_{B}\right)$.

Total capital supply is given by

$$
n+m=\sum k_{A i}\left(\rho+\tau_{A i}\right)+K_{B}\left(\rho+T_{B}\right),
$$

with $\rho=\rho\left(t_{i=1, \ldots, n} ; T_{A} ; T_{B}\right)$, from which follows that:

$$
\begin{array}{cc}
\frac{\partial \rho}{\partial t_{A i}}=-\frac{\frac{\partial k_{A i}}{\partial t_{A i}}}{\sum \frac{\partial k_{A i}}{\partial \rho}+\frac{\partial K_{B}}{\partial \rho}} & \in[-1 ; 0), \\
\frac{\partial \rho}{\partial T_{A}}=-\frac{\sum \frac{\partial k_{A i}}{\partial T_{A}}}{\sum \frac{\partial k_{A i}}{\partial \rho}+\frac{\partial K_{B}}{\partial \rho}} & \in[-1 ; 0),
\end{array}
$$

\footnotetext{
${ }^{14}$ Which is also why we are able to write $\rho_{A N A T}$ without an index in the first place.
} 


$$
\frac{\partial \rho}{\partial T_{B}}=-\frac{\frac{\partial K_{B}}{\partial T_{B}}}{\sum \frac{\partial k_{A i}}{\partial \rho}+\frac{\partial K_{B}}{\partial \rho}} \quad \in[-1 ; 0),
$$

and from the first two it can be inferred that

$$
\frac{\partial \rho}{\partial T_{A}}=n \frac{\partial \rho}{\partial t_{A i}}
$$

\subsection{Government Objectives}

The Leviathan governments in each jurisdiction aim to maximise tax revenues by choice of the respective tax rate, while taking into account the likely tax base reactions to given tax policies.

\subsubsection{State Level}

The state governments $i=1, \ldots, n$ in country $A$ hold the following objectives:

$$
\max _{t_{A i}} r_{i}=t_{A i} k_{A i}\left(\rho+\tau_{A i}\right)+\delta \pi\left(\rho+\tau_{A i}\right)
$$

Each state will set its tax rate taking those of all other states and the national jurisdictions (that act as Stackelberg leaders) as given, such that $t_{A i}=t_{A i}\left(t_{j \neq i=1, \ldots, n-1} ; T_{A} ; T_{B}\right)$. Using (1), each state's first-order-condition is given by

$$
\frac{\partial r_{A i}}{\partial t_{A i}}=k_{A i}\left(\rho+\tau_{A i}\right)+b_{i A}^{\prime}\left(\frac{\partial \rho}{\partial t_{A i}}+1\right)=0 .
$$

where we define $b_{i A}^{\prime}=\left(t_{A i} k_{A i}^{\prime}-\delta k_{A i}\right)<0$ as the change in regional tax base due to a respective tax hike, which follows the same argumentation as the previous section. It can be inferred from (7) that each regional government, just as in the previous section, will account for the direct tax revenue effect generated by choice of its tax rate (as depicted by the first term on the right hand side), as well as the tax base effect depicted by the second term in (7). It neglects that the latter will raise revenues in the other jurisdictions, thereby 
triggering a positive horizontal externality. Each state government further neglects that the federal tax base will possibly be negatively affected by capital not only relocating from one region to another within the federation, but also being shifted to country $B$. Thereby, the local entities will trigger a vertical externality which points towards state taxes being inefficiently high from the point of view of consolidated revenues. The symmetric setup of the states implies that equilibrium will be characterised by a symmetric solution in which all states set the same tax. We again consider the effect of a coordinated tax hike of all states on local government revenue to have

$$
\frac{\partial r_{A}}{n \partial t_{A}}=k_{A}\left(\rho+\tau_{A}\right)+b_{A}^{\prime}\left(n \frac{\partial \rho}{\partial t_{A}}+1\right) .
$$

In order to gain insight on the sign of (8), we substract (7) from (8), which yields

$$
\begin{aligned}
\frac{d r_{A}}{d t_{A}}=\frac{\partial r_{A}}{n \partial t_{A}}-\frac{\partial r_{A}}{\partial t_{A}} & =k_{A}\left(\rho+\tau_{A}\right)+t_{A} k_{A}^{\prime}\left(n \frac{\partial \rho}{\partial t_{A}}+1\right) \\
& -\delta k_{A}\left(n \frac{\partial \rho}{\partial t_{A}}+1\right)-k_{A}\left(\rho+\tau_{A}\right) \\
& -t_{A} k_{A}^{\prime}\left(\frac{\partial \rho}{\partial t_{A}}+1\right)+\delta k_{A}\left(\frac{\partial \rho}{\partial t_{A}}+1\right) \\
& =b_{A}^{\prime}(n-1) \frac{\partial \rho}{\partial t_{A}}>0
\end{aligned}
$$

That is, state revenues would increase as a consequence of a coordinated tax hike. This points towards state taxes being set inefficiently high (that is, not revenue-maximising) from the prespective of the regional Leviathan governments. It is in line with the results from section 3 and implies that the tax base effect from investors relocating their capital abroad is offset by the revenue effect.

\subsubsection{Federal Level}

Given the symmetric state equilibrium, the first-mover federal government's objective in $A$ is 


$$
\max _{T_{A}} R_{A}=n\left[T_{A} k_{A}\left(\rho+\tau_{A}\right)+\Delta \pi_{A}\left(\rho+\tau_{A}\right)\right]
$$

It bears in mind that regional governments will make their tax choice dependent on what rate was previously set at the federal level and takes the tax rate of the federal government in $B$ as given. It follows that $\rho=$ $\rho\left(t_{i=1, \ldots, n}\left(t_{j \neq i=1, \ldots, n-1} ; T_{A} ; T_{B}\right) ; T_{A} ; T_{B}\right)$ and its first-order condition will be given by

$$
\frac{\partial R_{A}}{\partial T_{A}}=n\left[k_{A}\left(\rho+\tau_{A}\right)+B_{A}^{\prime}\left(\frac{\partial \rho}{\partial T_{A}}+n \frac{\partial \rho}{\partial t_{A}} \frac{\partial t_{A}}{\partial T_{A}}+1+\frac{\partial t_{A}}{\partial T_{A}}\right)=0\right.
$$

in which $B_{A}^{\prime}=\left(T_{A} k_{A}^{\prime}-\Delta k_{A}\right)<0$ is the change in $A$ 's federal tax base due to a respective tax hike, analogous to the previous section. It follows from (10) that the federal government in $A$ will perfectly anticipate how its tax will affect the optimal choice of its regional governments and the corresponding impact on its tax base. It neglects the positive horizontal effect on tax base in $B$, thereby triggering a horizontal externality, which will become apparent further down.

Country B's government aims to satisfy

$$
\max _{T_{B}} R_{B}=n\left[T_{B} k_{B}\left(\rho+T_{B}\right)+\theta \pi_{B}\left(\rho+T_{B}\right)\right]
$$

for which also $\rho=\rho\left(t_{i}=1, \ldots, n\left(t_{j \neq i=1, \ldots, n-1} ; T_{A} ; T_{B}\right) ; T_{A} ; T_{B}\right)$. That is, it will perfectly anticipate that its own tax has an impact on the tax rate set by the regions in the neighbouring country. ${ }^{15}$ The first-order-condition is given by

\footnotetext{
${ }^{15}$ Within the existing literature on fiscal federalism, the assumptions made with respect to the extent to which one jurisdiction takes into account its competitors' reaction functions differ between the models and are subject to discussion. Of course, they essentially drive the generated results. In an early contribution, Keen (1998) examines taxation in a single federation where both levels of government are myopic. In a later paper, Keen and Kotsogiannis (2002) model a federation in which the decision-makers at each level are perfectly aware of the budget constraints at the other level. In a setting where two federations compete with each other, Wrede (2002) assumes for both levels in each federation to ignore the budget constraint of the other jurisdictions. Grazzini and Petretto (2007) analyse the interaction of a federal and a unitary country, where the federal-level
} 


$$
\begin{aligned}
\frac{\partial R_{B}}{\partial T_{B}}=n[ & k_{B}\left(\rho+T_{B}\right) \\
& \left.+\left(T_{B} k_{B}^{\prime}-\theta k_{B}\right)\left(\frac{\partial \rho}{\partial T_{B}}+n \frac{\partial \rho}{\partial t_{A}} \frac{\partial t_{A}}{\partial T_{B}}+1+\frac{\partial t_{A}}{\partial T_{B}}\right)\right]=0
\end{aligned}
$$

where $B_{B}^{\prime}=\left(T_{B} k_{B}^{\prime}-\theta k_{B}\right)<0$ is the change in $B$ 's federal tax base, and which works the same way as (10).

Equilibrium is characterised by $T_{A}=T_{A}\left(t_{i=1, \ldots, n}\left(t_{j \neq i=1, \ldots, n-1} ; T_{A} ; T_{B}\right) ; T_{B}\right)$ and $T_{B}=T_{B}\left(t_{i=1, \ldots, n}\left(t_{j \neq i=1, \ldots, n-1} ; T_{A} ; T_{B}\right) ; T_{A}\right)$, and further

$$
\rho=\rho\left[t_{i=1, \ldots, n}\left(t_{j \neq i=1, \ldots, n-1} ; T_{A} ; T_{B}\right) ; T_{A}\left(t_{i=1, \ldots, n}(\circ) ; T_{B}\right) ; T_{B}\left(t_{i=1, \ldots, n}(\circ) ; T_{A}\right)\right]
$$

In order to find out whether both governments will set their tax rates too high or too low in equilibrium, we again consider a coordinated tax rate hike between the two federal governments, which yields for country $A$ :

$$
\frac{\partial R_{A}}{\partial\left(T_{A}+T_{B}\right)}=n\left[k_{A}\left(\rho+\tau_{A}\right)+B_{A}^{\prime}\left(\frac{\partial \rho}{\partial T_{A}}+\frac{\partial \rho}{\partial T_{B}}+n \frac{\partial \rho}{\partial t_{A}} \frac{\partial t_{A}}{\partial T_{A}}+1+\frac{\partial t_{A}}{\partial T_{A}}\right)\right] .
$$

government in one country is assumed to be perfectly aware of the impact its own tax rate has on the taxes set by its regions and the government in the unitary country takes into account the tax rate set at the neighbouring country's federal level, but is ignorant of the interdependence with regional tax rates in that country. From our perspective, it is, however, just as likely that governments of one country do take the tax rates of neighbouring 'foreign' regions into account, irrespective of the jurisdictional level at which this rate is set. Take the case of corporate taxation in France and Germany: it is straightforward to argue that the French government, if it takes German corporate tax rates into account, will be aware of the effective tax burden and not limit its view to the federal level. What is more, the French government may be even more aware of the tax rates set in the different regions, particularly in those sharing borders with France. Our model may be restricted to symmetric equilibria across regions, yet that point still contributes to the validity of our assumption. Hence, while in general it may be a somewhat valid assumption for governments to be entirely ignorant of tax reactions in other jurisdictions, we do believe that if governments are assumed to be aware of each other's tax rates, then it must be mutually corresponding and should not be restricted to decisions taken at the same level. 
In order to determine the sign of (13), we substract (10), which is zero, from (13) to gain

$$
\frac{d R_{A}}{d T_{A}}-\frac{\partial R_{A}}{\partial T_{A}}=n\left[B_{A}^{\prime} \frac{\partial \rho}{\partial T_{B}}\right]>0
$$

That is, given the setup, federal revenues would increase following a coordinated tax hike at the federal level. Since the federal governments perfectly anticipate the reactions at the regional level, the result generated here is equivalent to that when only two unitary countries are competing. Unlike the case where only one isolated federal state is analysed, the optimising Stackelberg federal government neglects the horizontal effect triggered by its own tax rate on the neighbouring country's tax revenues. Hence, the federal governments in their turn cause a horizontal externality leading to tax rates being chosen such that they are not revenue-maximising. The same holds, obviously, from the perspective of government $B$.

\subsection{Cross-Jurisdictional Effects}

What is interesting with respect to the analysis of government behaviour in this setting are the effects triggered by a tax hike in one jurisdiction, as discussed earlier, on revenues at other levels or in other countries. In order to characterise these, we follow the approach taken by Grazzini and Petretto (2007) and also sugested by Wrede (2002). That is, the impact of a tax hike in one jurisdiction on revenues of another jurisdiction can be determined by assessing the change in equilibrium responses of that other jurisdiction. For the state level, $t_{A i}=t_{A i}\left(t_{j \neq i=1, \ldots, n-1} ; T_{A} ; T_{B}\right)$ for all $i$ in the federation. Using (12), the effect of a change in the tax rate at the federal level on regional budgets is then given by

$$
\frac{d r_{A}}{d T_{A}}=n \frac{\partial t_{A}}{\partial T_{A}} k_{A}\left(\rho+\tau_{A}\right)+b_{A}^{\prime}\left(\frac{\partial \rho}{\partial T_{A}}+n \frac{\partial \rho}{\partial t_{A}} \frac{\partial t_{A}}{\partial T_{A}}+1+n \frac{\partial t_{A}}{\partial T_{A}}\right) .
$$

Here, we can see that a tax hike at the federal level in $A$ will in turn affect the optimal choice of tax rates at the regional level $\left(\frac{\partial t_{A}}{\partial T_{A}}\right)$. That will have an impact directly on tax revenues as denoted by the first term on the right hand side of (15). Its sign depends on the assumptions made with respect to the 
strategic relationship between regional and federal tax rates. If we assume complementarity (ie. $\frac{\partial t_{A}}{\partial T_{A}}>0$ ), it will be positive, and negative otherwise. ${ }^{16}$ The second term denotes the tax base effect triggered by the tax hike at the federal level. Given that $b_{A}^{\prime}$ is clearly negative, its sign hinges on the last term in brackets. On the one hand, the tax base will be reduced as a consequence of the higher consolidated tax rate triggered by the federal hike and the resulting shift in optimal tax rates at the regional level $\left(1+n \frac{\partial t_{A}}{\partial T_{A}}\right)$. On the other hand, these shifts will each reduce the overall net return on capital, which will attenuate the direct negative tax base effect due to the tax hikes. That is, the impact of a federal tax hike on regional revenues is not necessarily negative. It depends on the strategic interaction of regional and federal tax rates. The obvious effect is the negative top-down externality resulting from the loss of regional tax base due to the higher consolidated tax burden. Then again, if, as a response to the federal hike, the regions choose to raise their tax rates (that is, if $\frac{\partial t_{A}}{\partial T_{A}}$ ), they will generate a positive tax revenue effect and at the same time further augment the tax base effect. The relative size of these two will then drive the sign of (15). If it is greater than zero, it points towards federal tax rates being inefficiently low. If it is less than zero, it points towards the vertical externality leading to federal tax

\footnotetext{
${ }^{16}$ The strategic relationship between tax rates of different jurisdictions is of course subject to discussion. The reaction curve estimated for horizontal interaction tends to be upward-sloping (see, for example, Besley and Case (1995), Brett and Pinske (2000), Buettner (2001) or Reulier and Feld (2009)), such that for cross-national and horizontal effects it is a fair approach to assume strategic complementarity. In a federal setting, it is, however, not unlikely for the federal government to set its tax rate optimal given state taxation, which might include lowering its tax as a response to a state-level tax hike in order for a consolidated tax burden not to be exceeded - especially if the federal government bears the federation's relative position to other countries in the international context in mind. That would point towards the assumption of federal and regional governments being strategic substitutes. The empirical evidence for federal interaction is mixed. There is evidence in favour of that hypothesis, such as Goodspeed (2000) or Hayashi and Boadway (2001). Some studies generate mixed results depending on the tax considered, for example, Wu and Hendrick (2009). Yet there seems to be a tendency towards studies suggesting the existence of an upward-sloping reaction curve also in the context of federal taxation, as in Besley and Rosen (1998), Esteller-Moré and Solé-Ollé (2001, 2002). For an overview of existing studies, see Brueckner (2003) or Rizzo (2010). In our case, with the consideration of revenue-maximising Leviathan governments focusing only on their own budgets, the assumption of strategic complementarity might be sensible. In what follows, we will focus on the case of strategic complementarity, but point towards the implication of different assumptions where applicable.
} 
rates being inefficiently high from the perspective of the revenue-maximising regional Leviathan government. In order to determine the sign of (15), we apply (6) and rewrite it as

$$
\frac{d r_{A}}{d T_{A}}=\frac{\partial t_{A}}{\partial T_{A}} k_{A}\left(\rho+\tau_{A}\right)+b_{A}^{\prime}\left(\frac{\partial \rho}{\partial T_{A}}\left(1+\frac{\partial t_{A}}{\partial T_{A}}\right)+1+n \frac{\partial t_{A}}{\partial T_{A}}\right) .
$$

Here, it becomes clear that the last term in brackets will be unambiguously greater than zero, if tax rates are strategic complements, given that $0<$ $\frac{\partial \rho}{\partial T_{A}}<-1$ and $1+n \frac{\partial t_{A}}{\partial T_{A}}>1+\frac{\partial t_{A}}{\partial T_{A}}$. Hence, the two terms on the RHS of (16) have opposite signs, such that the total effect depends on the relative magnitude of the tax income effect generated from the shift in regional level tax rates, as opposed to the tax base effect triggered from the reaction of investors to the changed investment conditions in the respective jurisdiction. That is, depending on whether we assume the reaction of tax rates to be more elastic than the reaction of the tax base towards a change in net return on capital, one effect will outweigh the other.

A coordinated tax hike by the regions in $A$, as considered in section 4.2.1, will affect equilibrium federal revenue as follows, bearing in mind that $T_{A}=$ $T_{A}\left(t_{i=1, \ldots, n}\left(t_{j \neq i=1, \ldots, n-1} ; T_{A} ; T_{B}\right) ; T_{B}\right)$ and $T_{B}=T_{B}\left(t_{i=1, \ldots, n}\left(t_{j \neq i=1, \ldots, n-1} ; T_{A} ; T_{B}\right) ; T_{A}\right)$ :

$$
\begin{aligned}
\frac{d R_{A}}{d t_{A}}=n[ & k_{A}\left(\rho+\tau_{A}\right) \frac{\partial T_{A}}{\partial t_{A}} \\
& \left.+B_{A}^{\prime}\left(n \frac{\partial \rho}{\partial t_{A}}+n \frac{\partial \rho}{\partial T_{A}} \frac{\partial T_{A}}{\partial t_{A}}+n \frac{\partial \rho}{\partial T_{B}} \frac{\partial T_{B}}{\partial t_{A}}+1+\frac{\partial T_{A}}{\partial t_{A}}\right)\right]
\end{aligned}
$$

from which we can infer that the equilibrium responses of national tax rates in both countries will change as a consequence of a coordinated tax rate hike at the regional level $\left(\frac{\partial T_{A}}{\partial t_{A}}\right.$ and $\left.\frac{\partial T_{B}}{\partial t_{A}}\right)$. A's change in federal tax rate will have a direct income effect, depending on the strategic relationship between national-level and regional-level tax rates, as depicted by the first term in squared brackets. The tax base effect will again be driven by the tax hike at the regional level and the resulting shift in the optimal federal tax rate. Further, investors will relocate their investments due to a change in net return to capital, which is triggered by the tax hike at the regional level as well as by the change in optimal tax rates set at the federal level in $A$ and in $B$. The sign of the latter is in turn driven by the strategic relationship of $T_{A}$ 
and $T_{B}$ with $t_{A}$ and will either augment the impact of the regional tax on $\rho$ (if $\frac{\partial T_{A}}{\partial t_{A}}>0$ and $\frac{\partial T_{B}}{\partial t_{A}}>0$ ) or otherwise attenuate it. Assuming again for tax rates to be strategic complements, it becomes apparent that the sign of the tax base effect and, thus, the sign of (17), will again hinge on the magnitude of the reduction in net return on capital in contrast to the tax hikes at the federal and regional level. Rewriting (17) yields

$$
\begin{aligned}
\frac{d R_{A}}{d t_{A}}=n[ & k_{A}\left(\rho+\tau_{A}\right) \frac{\partial T_{A}}{\partial t_{A}} \\
& \left.+B_{A}^{\prime}\left(\frac{\partial \rho}{\partial T_{A}}\left(1+n \frac{\partial T_{A}}{\partial t_{A}}\right)+1+n \frac{\partial T_{A}}{\partial t_{A}}+n \frac{\partial \rho}{\partial T_{B}} \frac{\partial T_{B}}{\partial t_{A}}\right)\right]
\end{aligned}
$$

We can see that given $-1<\frac{\partial \rho}{\partial T_{A}}<0$, it follows that $\frac{\partial \rho}{\partial T_{A}}\left(1+n \frac{\partial T_{A}}{\partial t_{A}}\right)+1+$ $n \frac{\partial T_{A}}{\partial t_{A}}$ will be greater than zero, such that the sign of the tax base effect is ambiguous. It will be negative, such that (18) becomes positive, if the elasticity of the federal tax rate in $B$ as a response to the tax regime change in $A$ is sufficiently large for the total effect on the tax base in $A$ (triggered by tax hikes on both levels and attenuated by the corresponding drop in the net return on capital) to be offset. Otherwise, the tax base effect will be negative, such that the sign of (18) depends on the relative magnitudes of the tax base effect and the direct tax income effect in $A$. Now, what this tells us is that if regions in $A$ agree upon a revenue-increasing tax hike, on the one hand, for assumed strategic complementarity of tax rates, the federal government will realise an increase in tax income, which could be named a positive bottom-up vertical externality. On the other hand, the coordinated hike will cause a reduction in tax base due to the higher tax burden and the lower net return to capital, which we might call a first-order negative vertical externality. What is more, that effect will be enhanced by the complementary reaction of federal tax rates in $A$, but on the other hand offset to a certain degree by the complementary reaction of national tax rates in $B$ (due to which country $A$ becomes in turn more attractive for investors). The relative magnitude of these last two effects drives the sign of the total tax base effect. ${ }^{17}$ Consider the (possibly more likely) case where the

\footnotetext{
${ }^{17}$ That is, the across-country vertical externality resulting from a regional-level tax hike may act by limiting the reduction of federal revenues in $A$. Put differently, by raising taxes, $A$ 's regional governments could attenuate the horizontal externalities triggered by across-border tax competition at the federal level.
} 
government's reaction in $B$ is not sufficiently strong for the tax base effect of the coordinated hike and the resulting hike at the federal level to be offset: Then the impact of a coordinated regional tax hike on federal revenues in $A$ in turn depends on whether the tax income effect realised by the federal government is sufficiently large to outweigh the tax base reduction, which again hinges on how elastic capital owners react towards a given change in tax regime. ${ }^{18}$

With respect to the cross-national effects of tax hikes, the impact of a federal tax hike in $B$ on regional budgets is given by

$$
\frac{d r_{A}}{d T_{B}}=n \frac{\partial t_{A}}{\partial T_{B}} k_{A}\left(\rho+\tau_{A}\right)+b_{A}^{\prime}\left(\frac{\partial \rho}{\partial T_{B}}+n \frac{\partial \rho}{\partial t_{A}} \frac{\partial t_{A}}{\partial T_{B}}+\frac{\partial t_{A}}{\partial T_{B}}\right) .
$$

Here, obviously, the tax base effect tends to be positive, albeit it is at least alleviated by the triggered shift in optimal regional tax rates, if we assume strategic complementarity. The impact is further amplified by the corresponding tax income effect. Depending on how pronounced that reaction in $A$ will be, the positive tax base effect may even be inverted, such that the overall sign would then again hinge on the relative size of tax revenue and tax base effect. Notwithstanding the interesting implications, this would, of course, call for quite extreme reactions by the Leviathan governments in $A$. Yet such an effect is theoretically possible. With respect to the magnitude of tax rate reactions, it is further interesting to note that $\frac{\partial t_{A}}{\partial T_{B}}$ is likely to be rather small. In any case, compared to (16), it seems reasonable to assume that the cross-national elasticities differ from the inner-national elasticities (ie. $\frac{\partial t_{A}}{\partial T_{B}} \neq \frac{\partial t_{A}}{\partial T_{A}}$ ). For example, German 'Laender' might react differently with respect to a tax rate hike at the federal level as opposed to a tax rate hike of national tax rates in France. Not only may this be due to the fact that the awareness of tax base reactions may not be the same across nations. What is more, depending on the regional proximity to France, some

\footnotetext{
${ }^{18}$ Obviously, one might argue that the assumption of strategic complementarity of tax rates across all jurisdictions does not make much sense. The federal government might rather choose to react towards a coordinated hike at the regional level by lowering its tax rate in order for a more favourable international position to be achieved. The model does give the necessary tools to analyse such behaviour at the federal level, but the discussion of all possible types of reactions would be beyond the scope of this paper and is left to the interested reader.
} 
regions may be quite directly affected by tax rates set in France (take Saarland or Baden-Wuerttemberg, for example), while others (such as Saxonia or Schleswig-Holstein) are not. These former regions' tax bases will then again be directly affected by different tax regimes in France, to which they might have an incentive to react. On the other hand, they will still be competing with other German regions, which, for their part, might have no intention of directly reacting towards taxes set in France, given that the impact on their tax base is rather limited. Hence, cross-national elasticities may differ across regions within one country and, on average, be lower than inner-national elasticities. This would, of course, make a case for the consideration of nonsymmetric equilibria, yet in the same time corroborates the assumption of a difference in 'average' sensitivity with respect to foreign national tax rates.

Likewise, the impact of an isolated tax hike in $B$ on the federal budget in $A$ is described by

$$
\begin{aligned}
\frac{d R_{A}}{d T_{B}}=n[ & k_{A}\left(\rho+\tau_{A}\right) \frac{\partial T_{A}}{\partial T_{B}} \\
& \left.+B_{A}^{\prime}\left(\frac{\partial \rho}{\partial T_{B}}+n \frac{\partial \rho}{\partial t_{A}} \frac{\partial t_{A}}{\partial T_{B}}+\frac{\partial \rho}{\partial T_{A}} \frac{\partial T_{A}}{\partial T_{B}}+\frac{\partial T_{A}}{\partial T_{B}}+\frac{\partial t_{A}}{\partial T_{B}}\right)\right]
\end{aligned}
$$

for which similar argumentations regarding the direct revenue and the tax base effect hold as for (19), except that the triggered change in federal tax rates and the change in tax rates set by the following regions further attenuate the latter. Hence, cross-national strategic reactions will in both cases lead to the positive impact of a tax hike in $B$ on revenues in the respective jurisdictional level in $A$ to be depleted by the strategic reaction of $A$ 's jurisdictions. $^{19}$

The impact of a federal tax hike in $A$ on revenues in $B$ is given by

$$
\begin{aligned}
\frac{d R_{B}}{d T_{A}}= & n\left[k_{B}\left(\rho+T_{B}\right) \frac{\partial T_{B}}{\partial T_{A}}\right. \\
& \left.+B_{B}^{\prime}\left(\frac{\partial \rho}{\partial T_{A}}+n \frac{\partial \rho}{\partial t_{A}} \frac{\partial t_{A}}{\partial T_{A}}+\frac{\partial \rho}{\partial T_{B}} \frac{\partial T_{B}}{\partial T_{A}}+\frac{\partial T_{B}}{\partial T_{A}}+n \frac{\partial T_{B}}{\partial t_{A}} \frac{\partial t_{A}}{\partial T_{A}}\right)\right]
\end{aligned}
$$

\footnotetext{
${ }^{19}$ If we assumed strategic substitutability of tax rates, of course, the question to be asked would be whether the negative direct revenue effect thus triggered could be offset by the further amplification of the tax base effect.
} 
which basically follows the same line of argumentation as (20), except that it might again be possible that $\frac{\partial t_{A}}{\partial T_{A}} \neq \frac{\partial t_{A}}{\partial T_{B}}$, such that (20) and (21) might differ.

\subsection{Total Revenue Effects}

Let us assume that the Leviathan governments of a country are required to provide a certain share of their revenues to the citizenship, which will be used for the provision of public goods. Then, the inhabitants of that country will be positively affected by the chosen policies and the question whether any tax reform will maximise total revenues within the entire federation becomes relevant. The total effect of a coordinated tax hike by the regions in $A$ is given by

$$
\begin{aligned}
\frac{d R_{A}}{d t_{A}}+\frac{d r_{A}}{d t_{A}}=n[ & k_{A}\left(\rho+\tau_{A}\right) \frac{\partial T_{A}}{\partial t_{A}} \\
& \left.+B_{A}^{\prime}\left(\frac{\partial \rho}{\partial T_{A}}\left(1+n \frac{\partial T_{A}}{\partial t_{A}}\right)+1+n \frac{\partial T_{A}}{\partial t_{A}}+n \frac{\partial \rho}{\partial T_{B}} \frac{\partial T_{B}}{\partial t_{A}}\right)\right] \\
& +b_{A}^{\prime}(n-1) \frac{\partial \rho}{\partial t_{A}}
\end{aligned}
$$

in which the effect on regional budgets (third line) is clearly positive and that on federal budgets (first two lines) is ambiguous. Whether or not the entire term becomes positive, depends on the elasticity of the tax regime in $B$ with respect to the tax rate chosen in the regions of country $A$. If the latter is sufficiently large, the total effect is positive and consolidated revenues will rise following a tax hike at the regional level. If it is not, the sign of (22) hinges on the relative magnitudes of the tax base effect as opposed to the income effect generated from the tax hike as well as that of the (positive) effect on revenues in the regions. (22) can be rewritten as

$$
\begin{aligned}
\frac{d R_{A}}{d t_{A}}+\frac{d r_{A}}{d t_{A}}=n[ & k_{A}\left(\rho+\tau_{A}\right) \frac{\partial T_{A}}{\partial t_{A}} \\
& +B_{A}^{\prime}\left(\frac{\partial \rho}{\partial T_{A}}\left(1+n \frac{\partial T_{A}}{\partial t_{A}}\right)+1+n \frac{\partial T_{A}}{\partial t_{A}}+n \frac{\partial \rho}{\partial T_{B}} \frac{\partial T_{B}}{\partial t_{A}}\right) \\
& \left.b_{A}^{\prime}\left(\frac{1}{n}-\frac{1}{n^{2}}\right)\left(\frac{\partial \rho}{\partial T_{A}}\right)\right]
\end{aligned}
$$


where it can be seen that for $n$ sufficiently large, the second term becomes zero, such that the sign of (23) is defined in the same way as (18).

The effect of a federal tax hike on consolidated revenues is depicted by

$$
\begin{aligned}
\frac{d R_{A}}{d T_{A}}+\frac{d r_{A}}{d T_{A}}=n[ & \left.B_{A}^{\prime} \frac{\partial \rho}{\partial T_{B}} \frac{\partial T_{B}}{\partial T_{A}}\right]+ \\
& \frac{\partial t_{A}}{\partial T_{A}} k_{A}\left(\rho+\tau_{A}\right)+ \\
& b_{A}^{\prime}\left(\frac{\partial \rho}{\partial T_{A}}+n \frac{\partial \rho}{\partial t_{A}} \frac{\partial t_{A}}{\partial T_{A}}+1+\frac{\partial t_{A}}{\partial T_{A}}\right),
\end{aligned}
$$

which can also be expressed as

$$
\begin{aligned}
\frac{d R_{A}}{d T_{A}}+\frac{d r_{A}}{d T_{A}}=n[ & \left.B_{A}^{\prime} \frac{\partial \rho}{\partial T_{B}} \frac{\partial T_{B}}{\partial T_{A}}\right]+ \\
& \frac{\partial t_{A}}{\partial T_{A}} k_{A}\left(\rho+\tau_{A}\right)+ \\
& b_{A}^{\prime}\left(\frac{\partial \rho}{\partial T_{A}}\left(1+\frac{\partial t_{A}}{\partial T_{A}}\right)+1+\frac{\partial t_{A}}{\partial T_{A}}\right),
\end{aligned}
$$

where, if we assume strategic complementarity throughout, the first two lines will be clearly positive, while the third line will be negative. Whether or not the total effect is positive depends on whether the reduction of regional tax base in $A$ (due to the higher consolidated tax rate and the corresponding reduction in net return to capital) can by offset by the tax revenue gain at the regional level, which results from the higher regional tax rates and the increase in federal tax base triggered by the tax rate hike in $B$ as a response to the federal tax hike in $A$. That is, a clear prediction of whether a tax hike at the federal level would raise total revenues in $A$ cannot be given.

\section{$5 \quad$ Interaction of Two Federal States}

The next case considered is that of two federations competing for mobile tax base. The basic setup is the same as in the previous section, except that now, country $B$ also has a federal structure, such that in every country, each region's inhabitant has the choice of investing capital in any region $i=$ 
$1, \ldots, n$ of country $A$ or in any region $g=1, \ldots, m$ of country $B$ with capital tax rates set at both levels in both countries. The three stages of decisionmaking are characterised the following way: Both federal governments choose their tax rates first. Subsequently, the regional governments in $A$ and $B$ choose their tax rates taking the taxes set previously at the federal level as given. Then, the inhabitants of every region choose where to invest their capital.

\subsection{Capital Investment}

The investment decisions by each investor are characterised in line with those in section 4.1, except that we now also explicitly recognise the federal structure of country $B$. That is, capital supply in each region of country $B$ is given by

$$
k_{B g}=k_{B g N A T}+k_{g A}^{*},
$$

where $g=1, \ldots, m$ stands for each region in country $B, k_{B g N A T}$ denotes the amount of capital available in one region of country $B$ that is actually invested in country $B, k_{g A}^{*}$ depicts the amount of capital available in country $A$ that is invested in region $g$ of country $B$. The same applies for capital provision in $A$.

All capital invested inside region $i$ of country $A$ will be subject to the consolidated tax rate $\tau_{A i}=t_{A i}+T_{A}$. Analogously, all capital invested inside one region of $B$ will be taxed at rate $\tau_{B g}=t_{B g}+T_{B}$, where the first is the tax rate levied by region $g$ and the latter denotes the tax rate levied by the federal government in country $B$. Investment decisions will be such that

$$
\begin{aligned}
& \rho_{A N A T}=f^{\prime}\left(k_{A i}\right)-\tau_{A i}, \\
& \rho_{A I N T}=f^{\prime}\left(k_{B g}\right)-\tau_{B g}, \\
& \rho_{B N A T}=f^{\prime}\left(k_{B g}\right)-\tau_{B g}, \\
& \rho_{B I N T}=f^{\prime}\left(k_{A i}\right)-\tau_{A i},
\end{aligned}
$$

which follows the same lines as in section 4.1. 
Non-arbitrage will again lead to the net return on capital being equalised across jurisdictions, such that total capital supply is now given by

$$
n+m=\sum k_{A i}\left(\rho+\tau_{A i}\right)+\sum k_{B g}\left(\rho+\tau_{B g}\right),
$$

with $\rho=\rho\left(t_{A i=1, \ldots, n} ; T_{A} ; T_{B} ; t_{B g=1, \ldots, m}\right)$, from which follows that:

$$
\begin{aligned}
& \frac{\partial \rho}{\partial t_{A i}}=-\frac{\frac{\partial k_{A i}}{\partial t_{A i}}}{\sum \frac{\partial k_{A i}}{\partial \rho}+\sum \frac{\partial k_{B g}}{\partial \rho}}<0 \quad \in[-1 ; 0), \\
& \frac{\partial \rho}{\partial T_{A}}=-\frac{\sum \frac{\partial k_{A i}}{\partial T_{A}}}{\sum \frac{\partial k_{A i}}{\partial \rho}+\sum \frac{\partial k_{B g}}{\partial \rho}}<0 \quad \in[-1 ; 0), \\
& \frac{\partial \rho}{\partial t_{B g}}=-\frac{\frac{\partial k_{B g}}{\partial t_{B g}}}{\sum \frac{\partial k_{A i}}{\partial \rho}+\sum \frac{\partial k_{B g}}{\partial \rho}}<0 \quad \in[-1 ; 0), \\
& \frac{\partial \rho}{\partial T_{B}}=-\frac{\sum \frac{\partial k_{B}}{\partial T_{B}}}{\sum \frac{\partial k_{A i}}{\partial \rho}+\sum \frac{\partial k_{B g}}{\partial \rho}}<0 \quad \in[-1 ; 0) .
\end{aligned}
$$

It also follows that

$$
\frac{\partial \rho}{\partial T_{A}}=n \frac{\partial \rho}{\partial t_{A i}}
$$

and

$$
\frac{\partial \rho}{\partial T_{B}}=m \frac{\partial \rho}{\partial t_{B g}} .
$$

\subsection{Government Objectives}

\subsubsection{State Level}

We will analyse the government decisions from the perspective of country $A$, given that the federal setup of both $A$ and $B$ is such that the effects 
will be the same irrespective of the perspective taken. Each region aims to maximise revenues by choice of its tax rate, while taking taxes set in the other regions (also those of country $B$ ) and federal tax rates as given, such that $t_{A i}=t_{A i}\left(t_{A j \neq i=1, \ldots, n-1} ; T_{A} ; T_{B} ; t_{B g=1, \ldots, m}\right)$. The objective is again

$$
\max _{t_{A i}} r_{i}=t_{A i} k_{A i}\left(\rho+\tau_{A i}\right)+\delta \pi_{A i}\left(\rho+\tau_{A i}\right),
$$

where $\rho=\rho\left(t_{A i=1, \ldots, n} ; T_{A} ; T_{B} ; t_{B g=1, \ldots, m}\right)$ and each state's first-order-condition is given by

$$
\frac{\partial r_{A i}}{\partial t_{A i}}=k_{A i}\left(\rho+\tau_{A i}\right)+b_{A i}^{\prime}\left(\frac{\partial \rho}{\partial t_{A i}}+1\right)=0,
$$

from which we can draw the same conclusions as in section 4 . The analogous objective holds for regional budgets in $B$, such that

$$
t_{B g}=t_{B g}\left(t_{B h \neq g=1, \ldots, m-1} ; T_{A} ; T_{B} ; t_{i=1, \ldots, n}\right) .
$$

Hence, equilibrium will be characterised by the tax choices of every region in $A$ as well as in country $B$, which will each affect the net return on capital, such that

$$
\begin{gathered}
\rho=\rho\left[t_{A i=1, \ldots, n}\left(t_{A j \neq i=1, \ldots, n-1} ; T_{A} ; T_{B} ; t_{B g=1, \ldots, m}(\circ)\right) ; T_{A} ; T_{B} ;\right. \\
\left.t_{B g=1, \ldots, m}\left(t_{B h \neq g=1, \ldots, m-1} ; T_{A} ; T_{B} ; t_{A i=1, \ldots, n}(\circ)\right)\right] .
\end{gathered}
$$

Equilibrium will be characterised by symmetric strategies not only of the states in $A$ but also of those in $B$.

In order to find out whether or not tax rates established in the oneshot Nash game will be too high or too low from the perspective of the revenue-maximising Leviathan, we consider again a coordinated tax hike at the regional level. The equilibrium effect of a coordinated hike in $A$ on regional budgets in $A$ is given by

$$
\frac{\partial r_{A}}{n \partial t_{A}}=k_{A}\left(\rho+\tau_{A}\right)+b_{A}^{\prime}\left(n \frac{\partial \rho}{\partial t_{A}}+m \frac{\partial \rho}{\partial t_{B}} \frac{\partial t_{B}}{\partial t_{A}}+1\right)
$$


That is, the budget is not only affected by the reduction in the net return on capital due to the tax hike in $A$. That hike also triggers an adaption of chosen tax rates in all of $B$ 's regions, which will in turn affect the net return on capital, thereby reducing the loss of tax base following the hike in $A$. The optimising regional government does not take these horizontal effects into account. Substracting (27) from (28), we gain

$$
\frac{\partial r_{A}}{n \partial t_{A}}-\frac{\partial r_{A}}{\partial t_{A}}=b_{A}^{\prime}\left[(n-1) \frac{\partial \rho}{\partial t_{A}}+m \frac{\partial \rho}{\partial t_{B}} \frac{\partial t_{B}}{\partial t_{A}}\right] .
$$

Hence, the sign of (29) hinges on the assumed relationship between regional taxes in the two countries, that is, $\frac{\partial t_{B}}{\partial t_{A}}$. If we assume strategic complementarity, the total effect will be clearly positive, which is in accordance with the standard result ${ }^{20}$ stating that the Leviathan government would profit from a rise in tax rates. ${ }^{21}$ That would point towards tax rates being set inefficiently low from the perspective of the revenue-maximising regional Leviathan government. In contrast, if tax rates are strategic substitutes, the revenue effect depends on the elasticity of tax rates in $B$ towards those set in $A\left(\frac{\partial t_{B}}{\partial t_{A}}\right)$, as well as on the relative size of both countries. The larger $B$ is compared to $A$, the more likely its reaction towards tax hikes in $A$ will be to offset the revenue-increasing effect of that tax hike for $A$.

If there was a chance for binding across-country agreements, the effect of a coordinated hike of all regions both in $A$ and in $B$ on the budget of a representative region in $A$ would be given by:

$$
\frac{\partial r_{A}}{\partial\left(n t_{A}+m t_{B}\right)}=k_{A}\left(\rho+\tau_{A}\right)+b_{A}^{\prime}\left(n \frac{\partial \rho}{\partial t_{A}}+m \frac{\partial \rho}{\partial t_{B}}+1\right)
$$

where the difference to (29) is that $\frac{\partial t_{B}}{\partial t_{A}}=1$. Substracting (27) from (30) yields

\footnotetext{
${ }^{20}$ See, for example, Keen and Kotsogiannis (2003).

${ }^{21}$ From (29) it becomes apparent that, under the assumption of strategic complementarity of regional tax rates across countries, it would always be revenue-enhancing for the Leviathan government to raise tax rates. That is, even if regional governments in one country do not have any across-country tax agreements, they can still profit from a unilateral tax rise within their own jurisdiction if the strategic reaction of the other country is complementary. Obviously, such behaviour would not lead to an equilibrium.
} 


$$
\frac{d r_{A}}{d t_{A}}=\frac{\partial r_{A}}{\partial\left(n t_{A}+m t_{B}\right)}-\frac{\partial r_{A}}{\partial t_{A}}=b_{A}^{\prime}\left[(n-1) \frac{\partial \rho}{\partial t_{A}}+m \frac{\partial \rho}{\partial t_{B}}\right]>0
$$

That is, regional budgets in $A$ (and $B$ ) would clearly increase following a coordinated tax hike in both countries. Hence, horizontal tax competition again seems to restrain Leviathan governments in their revenue-maximising ambitions.

\subsubsection{Federal Level}

The federal government in country $A$ chooses its own tax rate taking that of the other country's federal decision-maker as given. It is aware of the fact that the lower-level tax rates are set as functions of all the other tax rates, which it will perfectly anticipate, not only for all of its own regions, but also for all regions of country $B$. The federal government in $B$ faces the same situation, from which we can infer that

$$
\begin{gathered}
T_{A}=T_{A}\left[t_{i=1, \ldots, n}\left(t_{j \neq i=1, \ldots, n-1} ; T_{A} ; T_{B} ; t_{g=1, \ldots, m}\right) ; T_{B}\right. \\
\left.t_{g=1, \ldots, m}\left(t_{h \neq g=1, \ldots, m-1} ; T_{A} ; T_{B} ; t_{i=1, \ldots, n}\right)\right]
\end{gathered}
$$

and

$$
\begin{gathered}
T_{B}=T_{B}\left[t_{i=1, \ldots, n}\left(t_{j \neq i=1, \ldots, n-1} ; T_{A} ; T_{B} ; t_{g=1, \ldots, m}\right) ; T_{A} ;\right. \\
\left.t_{g=1, \ldots, m}\left(t_{h \neq g=1, \ldots, m-1} ; T_{A} ; T_{B} ; t_{i=1, \ldots, n}\right)\right] .
\end{gathered}
$$

The objective of the federal government in $A$ can thus be described by

$$
\max _{T_{A}} R_{A}=n\left[T_{A} k_{A}\left(\rho+\tau_{A}\right)+\Delta \pi\left(\rho+\tau_{A}\right)\right],
$$

and its first order condition is given by

$$
\begin{aligned}
\frac{\partial R_{A}}{\partial T_{A}}= & n\left[k_{A}\left(\rho+\tau_{A}\right)\right. \\
& \left.B_{A}^{\prime}\left(\frac{\partial \rho}{\partial T_{A}}+n \frac{\partial \rho}{\partial t_{A}} \frac{\partial t_{A}}{\partial T_{A}}+n \frac{\partial \rho}{\partial t_{B}} \frac{\partial t_{B}}{\partial T_{A}}+1+n \frac{\partial t_{A}}{\partial T_{A}}\right)\right]=0
\end{aligned}
$$


That is, the federal government in $A$ will take into account the reaction at the regional level in response to its chosen tax rate. It will, however, neglect the fact that its tax regime affects the optimal choice of tax rate at the federal level in $B$. Hence, in equilibrium

$$
\begin{aligned}
\rho=\rho[ & t_{i=1, \ldots, n}\left(t_{j \neq i=1, \ldots, n-1} ; T_{A} ; T_{B} ; t_{g=1, \ldots, n}(\circ)\right) ; \\
& T_{A}\left(t_{i=1, \ldots, n}(\circ) ; T_{B} ; t_{i=1, \ldots, n}(\circ)\right) ; \\
& T_{B}\left(t_{i=1, \ldots, n}(\circ) ; T_{A} ; t_{i=1, \ldots, n}(\circ)\right) ; \\
& \left.t_{g=1, \ldots, n}\left(t_{h \neq g=1, \ldots, n-1} ; T_{A} ; T_{B} ; t_{i=1, \ldots, n}(\circ)\right)\right]
\end{aligned}
$$

and the equilibrium reaction in response to a tax hike in $A$ is depicted by

$$
\begin{aligned}
\frac{\partial_{e} R_{A}}{\partial_{e} T_{A}} & =n\left[k_{A}\left(\rho+\tau_{A}\right)\right. \\
& \left.+B_{A}^{\prime}\left(\frac{\partial \rho}{\partial T_{A}}+n \frac{\partial \rho}{\partial t_{A}} \frac{\partial t_{A}}{\partial T_{A}}+m \frac{\partial \rho}{\partial t_{B}} \frac{\partial t_{B}}{\partial T_{A}}+\frac{\partial \rho}{\partial T_{B}} \frac{\partial T_{B}}{\partial T_{A}}+1+n \frac{\partial t_{A}}{\partial T_{A}}\right)\right]
\end{aligned}
$$

We substract (33) from (35) to find out the sign of the latter, which yields

$$
\frac{d R_{A}}{d T_{A}}=\frac{\partial_{e} R_{A}}{\partial_{e}\left(T_{A}\right)}-\frac{\partial R_{A}}{\partial T_{A}}=n\left[B_{A}^{\prime} \frac{\partial \rho}{\partial T_{B}} \frac{\partial T_{B}}{\partial T_{A}}\right]
$$

Equation (36) captures the horizontal externality triggered by a tax hike at the federal level in $A$. Its sign essentially hinges on the assumption regarding the strategic relationship between federal tax rates in the two countries. Again, for strategic complements the horizontal externality will be positive, pointing towards tax rates being inefficiently low from the perspective of the revenue-maximising Leviathan government. If they are strategic substitutes, it will be negative.

If federal governments in both countries had an incentive to cooperate, the effect of a coordinated tax hike at the federal level in both countries on federal revenue in $A$ would be characterised by 


$$
\begin{aligned}
\frac{\partial R_{A}}{\partial\left(T_{A}+T_{B}\right)}= & n\left[k_{A}\left(\rho+\tau_{A}\right)+\right. \\
& +B_{A}^{\prime}\left(\frac{\partial \rho}{\partial\left(T_{A}+T_{B}\right)}+n \frac{\partial \rho}{\partial t_{A}} \frac{\partial t_{A}}{\partial\left(T_{A}+T_{B}\right)}\right. \\
& \left.\left.+m \frac{\partial \rho}{\partial t_{B}} \frac{\partial t_{B}}{\partial\left(T_{A}+T_{B}\right)}+1+n \frac{\partial t_{A}}{\partial\left(T_{A}+T_{B}\right)}\right)\right]
\end{aligned}
$$

Again, we substract (33) from (37) to find out the sign of the latter, which yields

$$
\begin{aligned}
\frac{d R_{A}}{d T_{A}+T_{B}}= & \frac{\partial R_{A}}{\partial\left(T_{A}+T_{B}\right)}-\frac{\partial R_{A}}{\partial T_{A}}= \\
& n\left[B_{A}^{\prime}\left(\frac{\partial \rho}{\partial T_{B}}+n \frac{\partial \rho}{\partial t_{A}} \frac{\partial t_{A}}{\partial T_{B}}+m \frac{\partial \rho}{\partial t_{B}} \frac{\partial t_{B}}{\partial T_{B}}\right)\right]
\end{aligned}
$$

Assuming for tax rates at the regional level in both countries to be strategic complements with respect to the tax rate set at the federal level in $B$, (38) will be greater than zero. On the other hand, if they were strategic substitutes, the sign would hinge on the elasticity of regional tax rates in both countries with respect to federal tax rates in $B$ as opposed to the effect on net return to capital triggered by the federal tax hike in $B$. That is, if we drop the assumption of tax rates being strategic complements, the revenue-increasing effect of a coordinated hike across countries is no longer clear.

\subsection{Cross-Jurisdictional Effects}

In order to determine the effects triggered by a tax hike at the federal or regional level on revenues generated at the other levels, we again consider the impact of the resulting changes in the equilibrium choices of tax rates on revenues. For a tax hike at the regional level in $A$, the effect on federal revenues in $A$ is characterised by

$$
\begin{aligned}
\frac{d R_{A}}{d t_{A}}= & n\left[k_{A}\left(\rho+\tau_{A}\right) \frac{\partial T_{A}}{\partial t_{A}}\right. \\
& \left.B_{A}^{\prime}\left(n \frac{\partial \rho}{\partial t_{A}}+m \frac{\partial \rho}{\partial t_{B}} \frac{\partial t_{B}}{\partial t_{A}}+\frac{\partial \rho}{\partial T_{A}} \frac{\partial T_{A}}{\partial t_{A}}+\frac{\partial \rho}{\partial T_{B}} \frac{\partial T_{B}}{\partial t_{A}}+1+\frac{\partial T_{A}}{\partial t_{A}}\right)\right]
\end{aligned}
$$


which, using (25) and (26), can be rewritten as

$$
\begin{aligned}
\frac{d R_{A}}{d t_{A}}= & n\left[k_{A}\left(\rho+\tau_{A}\right) \frac{\partial T_{A}}{\partial t_{A}}\right. \\
& \left.B_{A}^{\prime}\left(\frac{\partial \rho}{\partial T_{A}}\left(1+\frac{\partial T_{A}}{\partial t_{A}}\right)+1+\frac{\partial T_{A}}{\partial t_{A}}+\frac{\partial \rho}{\partial T_{B}}\left(\frac{\partial t_{B}}{\partial t_{A}}+\frac{\partial T_{B}}{\partial t_{A}}\right)\right)\right] .
\end{aligned}
$$

That is, the effect of a change in tax regime at the regional level in $A$ on the budget of the federal government in $A$ is driven by the elasticity of the reaction of tax rates at both levels in $B$ to the change in tax regime in $A$. (39) follows the same lines as (18) in the case of a federation competing with a unitary state, except that an additional vertical across-country effect results from the state level governments in $B$ reacting in their optimal response tax rates to the choices made by $A$ 's regional governments, thereby having an impact on federal revenues. In the case of strategic complementarity, the reactions at both levels in country $B$ will attenuate the tax base effects resulting from the tax rate increase in $A$. Not only will investors be faced with a reduction in net return to capital for investments due to the tax hike in $A$, they will also encounter less favourable investment conditions in the other country as a result of the strategic interaction in $A$ and $B$, which in turn reduces their incentive to relocate investments. That is, the cross-national effects at both levels will make it more likely for the tax hike at the regional level to raise federal revenues.

In order to assess the effect of a federal tax hike on regional budgets, we can characterise the resulting change in equilibrium tax choices by:

$$
\begin{aligned}
\frac{d r_{A}}{d T_{A}}= & k_{A}\left(\rho+\tau_{A}\right) \frac{\partial t_{A}}{\partial T_{A}} \\
& +b_{A}^{\prime}\left(\frac{\partial \rho}{\partial T_{A}}+n \frac{\partial \rho}{\partial t_{A}} \frac{\partial t_{A}}{\partial T_{A}}+m \frac{\partial \rho}{\partial t_{B}} \frac{\partial t_{B}}{\partial T_{A}}+1+\frac{\partial t_{A}}{\partial T_{A}}\right)
\end{aligned}
$$

which, using (25) and (26), can be rewritten as

$$
\begin{aligned}
\frac{d r_{A}}{d T_{A}}= & k_{A}\left(\rho+\tau_{A}\right) \frac{\partial t_{A}}{\partial T_{A}} \\
& +b_{A}^{\prime}\left(\frac{\partial \rho}{\partial T_{A}}\left(1+\frac{\partial t_{A}}{\partial T_{A}}\right)+1+\frac{\partial t_{A}}{\partial T_{A}}+m \frac{\partial \rho}{\partial t_{B}} \frac{\partial t_{B}}{\partial T_{A}}\right)
\end{aligned}
$$


The sign of (41) essentially hinges on the magnitude of $m \frac{\partial \rho}{\partial t_{B}} \frac{\partial t_{B}}{\partial T_{A}}$. Assuming again strategic complementarity of tax rates, that term will be negative. Just as in section 4.3, the rest of the second line of (41) will be positive. Hence, if that last effect is sufficiently large (that is, if regional tax rates in $B$ react sufficiently elastically towards a tax hike in $A$ to outweigh the total impact on the tax base triggered by the changes in regional and federal tax rates in $A$ ), the tax base effect and, hence, (41) will be positive, pointing towards federal taxation being inefficiently low for the regional Leviathans. ${ }^{22}$ Otherwise, the same argumentation holds as in section 4.3. That is, in contrast to the case of a federation competing with a unitary state, if two federations interact, the horizontal competition effect is made more significant by means of the additional reaction of state governments in country $B$. In consequence, just as before, a tax hike at the federal level becomes more likely to increase regional revenues, given that the corresponding reaction in $B$ 's regions may alleviate the loss of tax base. That implies that the existence of vertical externalities that leads to inefficiently high federal tax rates is made less significant through the across-country effects arising at both levels of $B$.

We can also discern the effect of a federal tax hike in $B$ on regional revenues in $A$ by

$$
\begin{aligned}
\frac{d r_{A}}{d T_{B}}= & k_{A}\left(\rho+\tau_{A}\right) \frac{\partial t_{A}}{\partial T_{B}} \\
& +b_{A}^{\prime}\left(\frac{\partial \rho}{\partial T_{B}}+n \frac{\partial \rho}{\partial t_{A}} \frac{\partial t_{A}}{\partial T_{B}}+n \frac{\partial \rho}{\partial t_{B}} \frac{\partial t_{B}}{\partial T_{B}}+\frac{\partial t_{A}}{\partial T_{B}}\right)
\end{aligned}
$$

for which the same reasoning holds as for (19), except that the positive effect on $A$ 's regional tax base is further intensified by the strategic reaction at the regional level in $B$.

The change in $A$ 's federal budgets following a shift in tax regime in country $B$ can be described by

\footnotetext{
${ }^{22}$ The magnitude of $m \frac{\partial \rho}{\partial t_{B}} \frac{\partial t_{B}}{\partial T_{A}}$ is also affected by the elasticity of the net return to capital with respect to $B$ 's regional tax rate, as well as $B$ 's relative size compared to $A$ (ie. $m$ opposed to $n$ ).
} 


$$
\begin{aligned}
\frac{d R_{A}}{d T_{B}}= & n\left[k_{A}\left(\rho+\tau_{A}\right) \frac{\partial T_{A}}{\partial T_{B}}\right. \\
& \left.+B_{A}^{\prime}\left(\frac{\partial \rho}{\partial T_{B}}+n \frac{\partial \rho}{\partial t_{A}} \frac{\partial t_{A}}{\partial T_{B}}+\frac{\partial \rho}{\partial T_{A}} \frac{\partial T_{A}}{\partial T_{B}}+n \frac{\partial \rho}{\partial t_{B}} \frac{\partial t_{B}}{\partial T_{B}}+\frac{\partial T_{A}}{\partial T_{B}}+\frac{\partial t_{A}}{\partial T_{B}}\right)\right]
\end{aligned}
$$

Here, the same conjectures hold as for (20), except that the tax base reduction is further attenuated by the possible change in the optimal choice of tax rates at the regional level of country $B$, which in turn leads to the total effect being more likely to be positive. Likewise, the effect of a tax hike at the regional level in $B$ on federal revenues in $A$ is given by

$$
\begin{aligned}
\frac{d R_{A}}{d t_{B}}= & n\left[k_{A}\left(\rho+\tau_{A}\right) \frac{\partial T_{A}}{\partial t_{B}}\right. \\
& \left.+B_{A}^{\prime}\left(n \frac{\partial \rho}{\partial t_{B}}+n \frac{\partial \rho}{\partial t_{A}} \frac{\partial t_{A}}{\partial t_{B}}+\frac{\partial \rho}{\partial T_{A}} \frac{\partial T_{A}}{\partial t_{B}}+\frac{\partial \rho}{\partial T_{B}} \frac{\partial T_{B}}{\partial t_{B}}+\frac{\partial t_{A}}{\partial t_{B}}+\frac{\partial T_{A}}{\partial t_{B}}\right)\right]
\end{aligned}
$$

which follows the same argumentation as (43).

\subsection{Total Revenue Effects}

The effect of a federal tax hike in $A$ on total revenues within the federation is described by

$$
\begin{aligned}
\frac{d R_{A}}{d T_{A}}+\frac{d r_{A}}{d T_{A}}= & n\left[B_{A}^{\prime}\left(\frac{\partial \rho}{\partial T_{B}} \frac{\partial T_{B}}{\partial T_{A}}\right)\right]+k_{A}\left(\rho+\tau_{A}\right) \frac{\partial t_{A}}{\partial T_{A}} \\
& +b_{A}^{\prime}\left(\frac{\partial \rho}{\partial T_{A}}\left(1+\frac{\partial t_{A}}{\partial T_{A}}\right)+1+\frac{\partial t_{A}}{\partial T_{A}}+n \frac{\partial \rho}{\partial t_{B}} \frac{\partial t_{B}}{\partial T_{A}}\right)
\end{aligned}
$$

which will be greater than zero, if the elasticity of tax rates in the neighbouring regions is sufficiently high, such that the overall tax base effect will be positive. Otherwise, the sign of (45) depends on the relative magnitudes of the tax base effect at the federal level and the tax revenue effect at the regional level (which are both positive) in contrast to the (negative) tax base 
effect at the regional level. These are in turn essentially driven by the relative magnitudes of the strategic reactions of tax rates in $A$ and $B$, respectively. We can describe the total effect of a regional tax hike in $A$ by

$$
\begin{aligned}
\frac{d R_{A}}{d t_{A}}+\frac{d r_{A}}{d t_{A}}= & n\left[k_{A}\left(\rho+\tau_{A}\right) \frac{\partial T_{A}}{\partial t_{A}}\right. \\
& +B_{A}^{\prime}\left(n \frac{\partial \rho}{\partial T_{A}}\left(1+\frac{\partial T_{A}}{\partial t_{A}}\right)+1+\frac{\partial T_{A}}{\partial t_{A}}+\frac{\partial \rho}{\partial T_{B}}\left(\frac{\partial t_{B}}{\partial t_{A}}+\frac{\partial T_{B}}{\partial t_{A}}\right)\right] \\
& b_{A}^{\prime}\left[(n-1) \frac{\partial \rho}{\partial t_{A}}+n \frac{\partial \rho}{\partial t_{B}} \frac{\partial t_{B}}{\partial t_{A}}\right]
\end{aligned}
$$

which will clearly be greater than zero, if the elasticity of tax rates at the federal and regional level in $B$ is sufficiently high. Otherwise, it depends on the relative magnitude of the tax base effect in $A$ 's regions and the revenue effect at the federal level (which are both positive) in contrast to the tax base effect at the federal level (which will then be negative).

\section{Summary and Discussion of Results}

The aim of this paper was to enhance the discussion of efficient capital taxation in the light of international capital market integration by examining the impact of a change in a country's institutional structure on tax setting. The model is restricted to a very basic setup. Notwithstanding its simplicity, it helps to specify each relative effect of a tax regime change in one particular jurisdiction. While the total impact of the specified effects is ambiguous, the results can be summarised as follows:

In the reference case of two competing unitary states, governments would profit from a coordinated tax hike, which points towards tax rates being set inefficiently low in equilibrium. This follows from the broadly discussed horizontal externalities caused by each government neglecting the positive effect their own tax rate choice might have on another country's tax base.

With the introduction of a federal layer in one of the countries, the upperlevel as well as the lower-level governments will be subject to horizontal tax competition and tend to set tax rates inefficiently low, that is, not revenuemaximising from their perspective, in equilibrium. The 'standard' negative vertical externality triggered by tax-setting at different levels of government 
within a federation (which points towards regional tax rates being set ineffciently high from the point of view of the federal Leviathan and vice versa) is then accompanied by positive cross-national vertical externalities from the regions of the federation to the upper-level unitary government (which point towards regional tax rates being set inefficiently low from the perspective of the foreign country) and vice versa. While it is easily validated that their own tax rates will be set inefficiently low from the perspective of each revenue-maximising Leviathan government, the results regarding the crossjurisdictional revenue effects and thus also the impact of a tax hike in one jurisdiction on consolidated revenues, are ambiguous. A tax hike in one jurisdiction triggers a tax base effect and a tax revenue effect in the other jurisdictions. The tax base effect is driven by the respective externalities just outlined. It tends to be negative for two jurisdictions at different levels within the same country. It tends to be positive for cross-national revenue effects of tax regime changes. The sign in each case hinges on the elasticity of the net return to capital and the elasticity of the tax rate response to a given tax rate change. The latter is incurred by the fact that the equilibrium tax rate for one jurisdiction will change given a tax hike in another jurisdiction, which may further augment or attenuate the tax base effect. That strategic reaction in tax rates also feeds into the tax income effect, which will be positive, if considered tax rates are strategic complements, and negative otherwise. Tax base effect and tax income effect tend to have opposite signs, such that the total impact of a tax reform in one jurisdiction on revenues in another jurisdiction (and, thus, the answer to the question whether the respective tax rates will be too high or too low from the perspective of the other jurisdiction) is ambiguous and essentially hinges on the relative elasticity of tax rates in contrast to the elasticity of the net return on capital to a given tax rate.

If both countries considered have a federal setup, the results change in such that another layer of cross-national effects will be incurred by a tax hike. For one, horizontal competition is intensified across borders at the regional level. The revenue-increasing effect of a coordinated tax hike within one country is then either attenuated or augmented depending on the assumed strategic reaction of regional tax rates in the other country. The federallevel governments are still subject to horizontal competition and tend to set taxes inefficiently low. The impact of a tax reform in one jurisdiction on 
revenues in other jurisdictions of other levels is again ambiguous. Basically, the same argumentation holds as in the previous case, except that the crossnational tax competition effects are now augmented by the strategic reaction of regions in the second federation.

The discussion can be summarised by stating that the classic results of federal taxation are altered when competition of two countries is explicitly modelled. For one, just as in Grazzini and Petretto (2007), the first-mover federal governments become subject to horizontal competition and subsequently tend to set taxes inefficiently low. The vertical externalities triggered at the regional level feed back not only to its own federal government (negative vertical externality), but also to that of the other country (positive vertical externality). In the reverse case, the regional government in one country is also subject to vertical externalities not only generated by the federal government at home, but also by that abroad, each pointing in different directions. The introduction of an additional layer of government in both countries further intensifies the horizontal tax competition effects in each jurisdiction. These cross-national interactions work by potentially counteracting the (vertical) tax externalities triggered within the home country. The explicit recognition of another competing country hence points towards the relevance of vertical tax externalities as a source of inefficiently high tax rates being reduced. The extent to which this occurs depends on the relative strategic relationship between tax rates in the respective jurisdictions, the sensitivity of that relationship and the relative size of the two countries considered. Notwithstanding some empirical support, the discussion in every section made it clear that it is far from satisfying to assume that all tax rates will be set as strategic complements. While this may be valid for the case of cross-country interactions, it need not be for the strategic interaction of federal and state level governments within one country. Furthermore, the magnitude of the tax rate responses, which drives the sign of the total effect, may also differ between jurisdictions. Given that the empirical evidence on the strategic interaction between different levels of government is mixed, it may be wise to try and depict the impact of tax regime changes bearing very carefully in mind the respective situation. Hence, the model provides an opportunity to have a rough estimate of the overall revenue effects triggered by a possible tax regime change, while allowing for very specific individual assumptions with respect to the strategic interaction of tax rates between 
different levels of government and countries to be made. 


\section{$7 \quad$ References}

Baskaran, Thushyanthan (2010), On the Link Between Fiscal Decentralization and Public Debt in OECD Countries, MPRA Paper No. 21599, Munich.

Berberich, Christina and Johannes Metzler (2005), Fiscal Federalism and the Leviathan: The Evil Beast or the Lesser Evil?, Kiel Advanced Studies Working Papers No. 422, Kiel.

Besley, Timothy J. and Harvey S. Rosen (1998), Vertical Externalities in Tax Setting: Evidence from Gasoline and Cigarettes, Journal of Public Economics 70, 383-398.

Besley, Timothy J. and Anne Case (1995), Incumbent Behaviour: VoteSeeking, Tax-Setting and Yardstick Competition, American Economic Review 85(1), 25-45.

Brennan, Geoffrey and James Buchanan (1977), Towards a Tax Constitution for Leviathan, Journal of Public Economics 8, 255-273.

Brennan, Geoffrey and James Buchanan (1980), Analytical Foundations of a Fiscal Constitution, Cambridge: Cambridge University Press.

Brett, Craig and Joris Pinske (2000), The Determinants of Municipal Tax Rates in British Columbia, Canadian Journal of Economics 33(3), 695714 .

Brueckner, Jan K. (2003), Strategic Interaction Among Governments: An Overview of Empirical Studies, International Regional Science Review 26 (2), 175-188.

Bruelhart, Marius and Mario Jametti (2007), Does Tax Competition Tame the Leviathan?, CEPR Discussion Papers 6512.

Buettner, Thiess (2001), Fiscal Externalities in Local Tax Competition: Empirical Evidence from a Panel of German Jurisdictions, ZEW Discussion Paper No. 01-11, Mannheim. 
Cassing, James H. and Arye L. Hillman (1982), State-Federal Resource Tax Rivalry: The Queensland Railway and the Federal Export Tax, Economic Record 58(162), 235-241.

Dahlby, Bev (1996), Fiscal Externalities and the Design of Intergovernmental Grants, International Tax and Public Finance 3, 397-412.

Davies, Ronald B. and Johannes Voget (2009), Tax Competition in an Expanding European Union, IIIS Discussion Paper No. 276, Dublin.

dePater, James A. and Gordon M. Myers (1994), Strategic Capital Tax Competition: A Pecuniary Externality and a Corrective Device, Journal of Urban Economics 36, 66-78.

Esteller-Moré, Álejandro and Albert Solé-Ollé (2001), Vertical Income Tax Externalities and Fiscal Interdependence: Evidence From the US, Regional Science and Urban Economics 31, 247-272.

Esteller-Moré, Álejandro and Albert Solé-Ollé (2002), Tax Setting in a Federal System: The Case of Personal Income Taxation in Canada, International Tax and Public Finance 9, 235-257.

European Union (2009), Press Release IP/09/19, access online under: http://europa.eu/rapid/pressReleasesAction.do?reference=IP/09/19 (July 19th 2010).

Feld, Lars and Emanuelle Reulier (2009), Strategic Tax Competition in Switzerland: Evidence from a Panel of the Swiss Cantons, German Economic Review 10 (1), 91-114.

Fenge, Robert and Matthias Wrede (2007), EU Financing and Regional Policy: Vertical Fiscal Externalities when Capital is Mobile, Public Finance Analysis vol. 63 no. 4.

Flowers, Marilyn R. (1988), Shared Tax Sources in a Leviathan Model of Federalism, Public Finance Quarterly 16, 67-77. 
Goodspeed, Timothy J. (2000), Tax Structure in a Federation, Journal of Public Economics 75, 493-506.

Grazzini, Lisa and Alessandro Petretto (2007), Tax Competition Between Unitary and Federal Countries, Economics of Governance 8, 17-36.

Hayashi, Masayoshi and Robin Boadway (2001), An Empirical Analysis of Intergovernmental Tax Interaction: The Case of Business Income Taxes in Canada, Canadian Journal of Economics 36(2), 481-503.

Johnson, William R. (1988), Income Redistribution in a Federal System, American Economic Review 78, 570-573.

Karkalakos, Sotiris and Miltiadis Makris (2008), Capital Tax Competition in the Euopean Union: Theory and Evidence from Two Natural Experiments, MPRA Working Paper No. 21437, Munich.

Keen, Michael (1998), Vertical Tax Externalities in the Theory of Fiscal Federalism, IMF Staff Papers 45, 454-485.

Keen, Michael and Christos Kotsogiannis (2002), Does Federalism Lead to Excessively High Taxes?, American Economic Review 92, 363-370.

Keen, Michael and Christos Kotsogiannis (2003), Leviathan and Capital Tax Competition in a Federation, Journal of Public Economic Theory 5, 177-199.

Mintz, Jack and Henry Tulkens (1986), Commodity and Tax Competition Between Member States of a Federation: Equilibrium and Efficiency, Journal of Public Economics 29, 133-172.

Oates, Wallace E. (1972), Fiscal Federalism, New York: Harcourt Brace Jovanovich.

Oates, Wallace E. (1985), Searching for Leviathan: An Empirical Study, American Economic Review 75(4), 748-757. 
Rizzo, Leonzio (2010), Interaction Between Federal Taxation and Horizontal Tax Competition: Theory and Evidence From Canada, Public Choice $144,369-387$.

Tiebout, Charles M. (1956), A Pure Theory of Local Expenditures, Journal of Political Economy 64, 416-424.

Tillmann, Lisa and Berthold U. Wigger (2010), Federal Taxation and International Capital Market Integration, mimeo.

Wigger, Berthold U. and Udo Wartha (2004), Vertical Tax Externalities and the Composition of Public Spending in a Federation, Economics Letters 84, 357-361.

Wildasin, David E. (1989), Interjurisdictional Capital Mobility: Fiscal Externality and a Corrective Subsidy, Journal of Urban Economics 25, 193-212.

Wildasin, David E. and John D. Wilson (2004), Capital Tax Competition: Bane or Boon, Journal of Public Economics 88, 1065-1091.

Wilson, John D. (1986), A Theory of Interregional Tax Competition, Journal of Urban Economics 19, 296-315.

Wilson, John D. (1999), Theories of Tax Competition, National Tax Journal 52(2), 269-304.

Wilson, John D. and Eckhard Janeba (2005), Decentralization and International Tax Competition, Journal of Public Economics 89, 1211-1229.

Wrede, Matthias (1996), Vertical and Horizontal Tax Competition: Will Uncoordinated Leviathans End Up on the Wrong Side of the Laffer Curve?, Finanzarchiv 53, 461-479.

Wrede, Matthias (2002), Fiskalische Externalitäten im föderativen Staat, Beiträge zur Finanzwissenschaft 13, Mohr-Siebeck. 
Wu, Yonghong and Rebecca Hendrick (2009), Horizontal and Vertical Tax Competition in Florida Local Governments, Public Finance Review 37, $289-311$.

Yeung, Ryan (2009), The Effects of Fiscal Decentralization on the Size of Government: A Meta-Analysis, Public Budgeting and Finance 29(4), $1-23$.

Zodrow, George R. and Peter Mieszkowski (1986), Pigou, Tiebout, Property Taxation, and the Underprovision of Local Public Goods, Journal of Urban Economics 19, 356-370. 